\title{
Autopsy: a powerful tool for teaching and learning
}

\author{
Maria Claudia Nogueira Zerbini ${ }^{a}$
}

Zerbini MCN. Autopsy: a powerful tool for teaching and learning. Autopsy Case Rep [Internet]. $2011 ; 1(2): 1-2$.

Autopsy provides an excellent tool for continuous education in Medicine.

During my first year of training in Pathology in the 70's, the most important activity was the clinicopathological meeting every morning in the autopsy room, supervised by Professor Thales de Brito. At these meetings the clinician presented a brief clinical summary and the main unsolved questions about the case. The radiologist presented the main images and the pathology resident presented the macroscopic findings on selected gross specimens. Most of the diagnoses were made based on an accurate gross examination, and oriented sections for microscopic analysis. During my fellowship at Harvard Medical School in the 90's, a very similar meeting was held at the Brigham and Women's Hospital, oriented by Professors Stanley Robbins and Ramzi Cotran. Dr. Cotran was the head of Pathology Department at that time. Medical students, pathology residents and fellows, radiologists, clinicians, and staff pathologists all participated in those important teaching sessions. But differently from Brazil, those autopsy meetings occurred weekly instead of daily, already reflecting the decline in the number of autopsies at that time in USA.

Nowadays, at the Hospital Universitário da Universidade de São Paulo, a similar autopsy meeting is held weekly. Some innovations were imple- mented such as the availability of macro and microscopic digital images displayed on a wide screen in the autopsy room, and the detailed dynamic radiologic images described by an expert radiologist. In fact, with the advance in high resolution image techniques, Radiology and Pathology share a very close relationship, and should be viewed as powerful complementary techniques to identify and map lesions for further histopathologic and molecular studies.

This meeting is a special moment in the Hospital life, when clinicians and pathologists exercise their medical skills, recognize their mistakes, make constructive criticism and raise questions about established concepts. Many achievements are obtained from this activity. From the pathology point of view, the quality and care of the autopsy procedure, the careful documentation of gross and microscopic findings, the contribution of the multidisciplinary discussion to the pathology report, and the timing of releasing the final report, are all remarkable improvements 3 years after this session started to happen. For the medical students and residents this is an opportunity to evaluate the importance of a welldocumented medical record, to review the diagnostic algorithms and consolidate pathophysiologic and clinical concepts. Interestingly, literature data reveal that prior exposure to autopsy in training practice influences physicians' attitudes positively in considering autopsy as a relevant clinical tool. ${ }^{1}$ These medi-

\footnotetext{
a Diretora do Serviço de Anatomia Patológica do Hospital Universitário - Universidade de São Paulo. Departamento de Patologia da Faculdade de Medicina - Universidade de São Paulo
}

Copyright $\odot 2011$ Autopsy and Case Reports - This is an Open Access article distributed of terms of the Creative Commons Attribution Non-Commercial License (http://creativecommons.org/licenses/by/3.0/) which permits unrestricted non-commercial use, distribution, and reproduction in any médium provided article is properly cited. 
cal students would be strong candidates to request autopsies in their clinical practice in the future.

In addition, autopsy is an important tool for quality assurance. A meta-analysis based on a College of American Pathologists survey of 248 Institutions in USA found that nearly half of the autopsies yield at least one unexpected finding that contributed to the patient's death. ${ }^{2}$ Although no study has directly addressed the impact of autopsy findings on clinical practice or performance

\section{REFERENCES}

1. Oluwasola OA, Fawole OI, Otegbayo AJ, et al. The autopsy: knowledge, attitude, and perceptions of doctors and relatives of the deceased. Arch Pathol Lab Med. 2009;133:78-82. improvement, the value of autopsy report for epidemiologic research and healthcare decisions is clearly demonstrated.

Finally, at autopsy meetings new ideas and research projects are generated, and this was the case of Autopsy and Case Reports, the electronic journal that was inspired by this atmosphere of teaching and learning - and should have all of our support to become the most important scientific periodical in this field.

2. Zarbo RJ, Baker PB, Howanitz PJ. The autopsy as a performance measurement tool: diagnostic discrepancies and unresolved clinical questions: a College of American Pathologists Q-Probes study of 2479 autopsies from 248 institutions. Arch Pathol Lab Med. 1999;123:191-8. 